\title{
Clinical features and outcomes of primary bone and soft tissue sarcomas in adolescents and young adults
}

\author{
KAZUHIKO HASHIMOTO, SHUNJI NISHIMURA, NAOHIRO OKA and MASAO AKAGI \\ Department of Orthopaedic Surgery, Kindai University Hospital, Osaka-Sayama, Osaka 589-8511, Japan
}

Received July 10, 2019; Accepted January 29, 2020

DOI: $10.3892 / \operatorname{mco} .2020 .1994$

\begin{abstract}
The aim of the present study was to investigate the clinical outcomes of adolescents and young adults with bone and soft tissue sarcomas. Records of seven male and six female patients aged 17-39 years with bone or soft tissue sarcomas were reviewed retrospectively; data on histology, size, location, grade/stage, treatment, recurrence, presence of metastasis, and prognosis were retrieved. Five-year survival rates were estimated using the Kaplan-Meier method and were compared according to age, sarcoma type, histological grade, and location. Seven and six patients had bone and soft tissue sarcomas, respectively. In terms of histology, patients with bone sarcomas included four with osteosarcoma, two with chondrosarcoma, and one with Ewing sarcoma of the bone. Of those with soft tissue sarcomas, three had liposarcomas, two had synovial sarcomas, and one each had Ewing sarcoma and leiomyosarcoma. The five-year survival rate of the cohort was $57.1 \%$. Younger patients with sarcoma had poorer survival than older patients. Patients with high-grade sarcomas also had poorer survival than those with low-grade tumors. In addition, patients with trunk-located tumors had poorer survival than those with tumors in the extremities. These findings suggest that, younger adolescents and young adults with high-grade or trunk-located sarcomas require more aggressive treatment.
\end{abstract}

\section{Introduction}

Bone and soft tissue sarcomas (BSTS) are connective tissue malignancies arising from tissues of mesenchymal origin (1). BSTS may occur in all age groups. However, it is not common in adolescents and young adults (AYAs) aged 15-39 years (2) with these tumors comprising only $6-8 \%$ of all malignancies in AYAs (3-5). The mortality rates among AYAs with BSTS are high as these types of cancer confer poorer prognoses than those of other types such as Hodgkin's lymphoma, melanoma,

Correspondence to: Dr Kazuhiko Hashimoto, Department of Orthopaedic Surgery, Kindai University Hospital, 377-2 Ohno-Higashi, Osaka-Sayama, Osaka 589-8511, Japan

E-mail: hazzhiko@med.kindai.ac.jp

Key words: clinical outcome, sarcoma, adolescents and young adults, bone, soft tissue or germ cell tumors (6). In AYA sarcomas also confer poorer prognoses than in both, younger and older patients, irrespective of the histological type (6-8). However, data from clinical investigations of the outcomes of AYA patients with BSTS are scarce (2,7-10).

In this study, we aimed to determine the survival rates of AYAs with BSTS at the Kindai University Hospital and the factors contributing to poorer prognosis in patients of this age group.

\section{Patients and methods}

Patients. The records of 7 male patients and 6 female patients aged 17-39 (mean: 34 years) with BSTS were reviewed retrospectively between October 2009 and July 2017. Data on the size, histological grade, location, stage, treatment modalities, local recurrence, presence of metastasis, and final outcomes were recorded. The resected specimens were stained with hematoxylin-eosin (H\&E). The histological grade was determined based on the four-point grading system for bone tumors (11) and the Federation Nationale des Centres de Lutte Contres le Cancer grading system for soft tissue tumors (12).

This study was approved by the Ethics Committee of Kindai University Hospital (approval no.: 31-153) (Osaka, Japan). All patients also provided written informed consent for the participation of this retrospective study.

Methods. The grading system for bone tumors, with the exception of Ewing sarcoma, was based on a previously described system (11). Tumors of grades 1-2 and 3-4 were considered as low- and high-grades, respectively. Among soft tissue tumors, lesions of grades 1 and 2-3 were classified as low- and high-grade, respectively. The clinical staging was individually evaluated based on the American Joint Committee on Cancer (AJCC) 7 th edition for soft tissue tumors and bone cancer $(13,14)$. The mean follow-up period was 45 (range: 11-111 months). Surgery was aimed at achieving wide surgical margins in all cases (Table I: 11/13 cases). The surgical margins in resected specimens were categorized as R0, R1, or R2, as previously classified (15). The patients' 5-year survival rates were calculated using the Kaplan-Meier method; and the 5-year survival rates of younger (15-29 years) and older ( $\geq 30)$ patients, as well as that of patients with bone vs. soft tissue sarcoma, low-vs. high-grade tumors, and trunk-vs. extremity-located tumors using log-rank tests. 


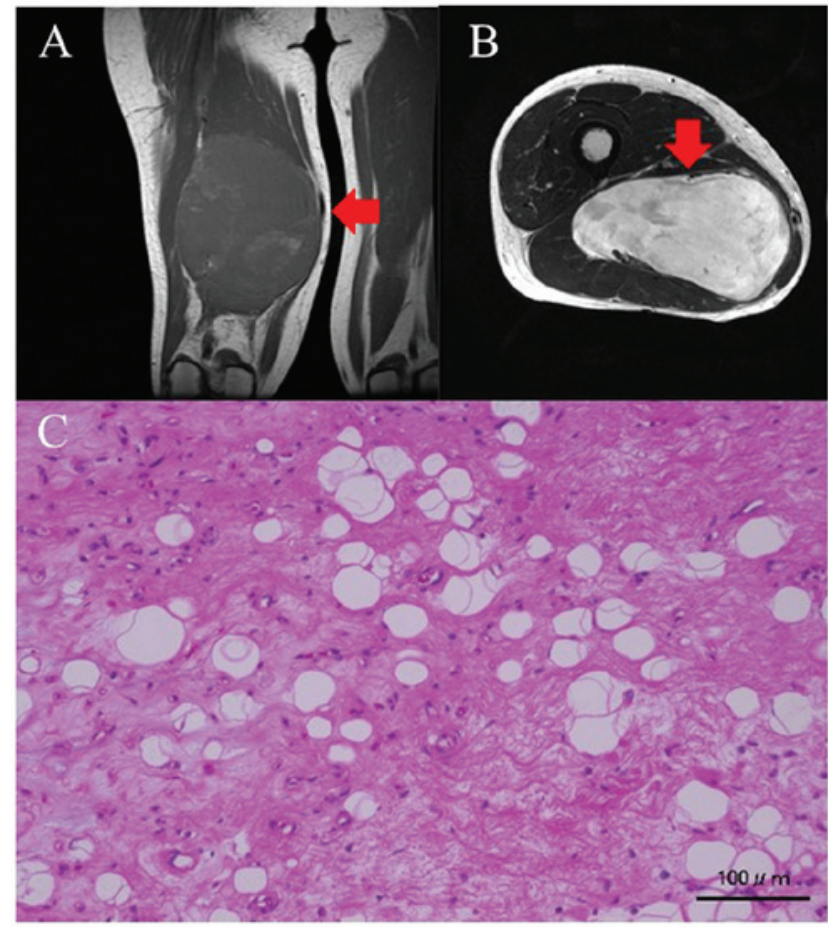

Figure 1. (A) Coronal T1-weighed MRI image of the thigh. The tumor intensity is low. (B) Transverse slices of T2-weighed MRI images of the thigh. The tumor intensity is high. (C) Histological findings on hematoxylin-eosin (H\&E) staining. Small atypical cells proliferating in the background of a mucus matrix. Some lipoblasts are also noted. Red arrows indicate the tumor mass. Scale bar, $100 \mu \mathrm{m}$

Statistical analysis. The Statmate 4.01 software package was used to assess the 5-year survival rates. The patients' 5-year survival rates were calculated using the Kaplan-Meier method and differences were assessed using the log-rank test. $\mathrm{P}<0.05$ was considered to indicate a statistically significant difference.

\section{Results}

Patients and treatment. Seven and six patients had bone and soft tissue sarcomas, respectively. Among those with bone sarcomas, four, two, and one had osteosarcoma, chondrosarcoma, and Ewing sarcoma, respectively; three had high-grade disease, while the tumors were of low grades in the remainder. Among the six patients with soft tissue sarcomas, three had myxoid liposarcoma, two had synovial sarcoma, and one had Ewing sarcoma; six and one had high- and low-grade disease, respectively (Table I). Nine sarcomas were located in the lower limbs, three were in the trunk, and one was in the upper limbs. Sarcomas in older patients were staged according to the AJCC criteria: Stage I ( $n=3)$, IIA ( $n=1)$, II $(n=3)$, III $(n=4)$, IV $(n=1)$, and IVB $(n=1)$. Lymph node metastases were observed during the first examination in 1 case (Table I; patient number 2). In addition, lung metastasis had developed in 3 cases during treatment (Table I; patient numbers 4, 6, and 13). A total of 11 patients underwent tumor resections (wide and marginal in 9 and 2, respectively). The surgical margin status was R0, $\mathrm{R} 1$, and $\mathrm{R} 2$ in 7, 3, and 1 cases, respectively (Table I). The remaining two patients did not undergo surgery owing to difficulties in accessing the pelvic tumor and extensive disease in 1 case each; these patients were treated with 5-6 courses

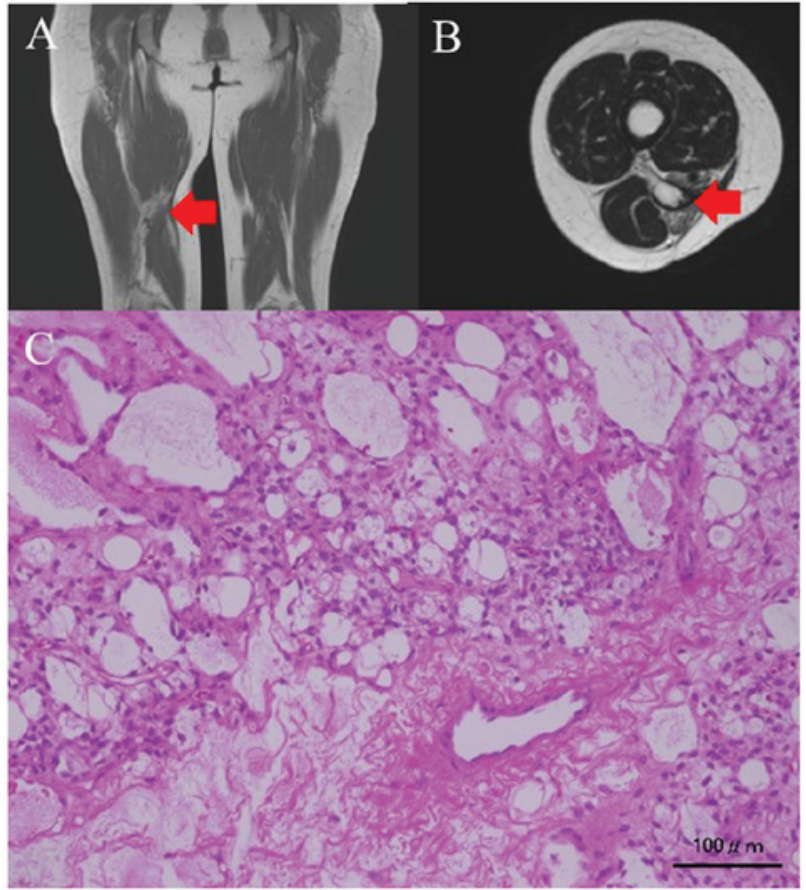

Figure 2. (A) Coronal T1-weighed MRI image of the thigh. The recurrence tumor intensity is low. (B) Transverse slices of T2-weighed MRI images of the thigh. The intensity of the recurrent tumor is high. (C) Histological findings on staining with hematoxylin-eosin (H\&E). Small or star-shaped atypical cells are found in the mucus matrix. Poorly differentiated proliferating lipoblasts with fat vacuoles are also noted. Red arrows indicate the tumor mass. Scale bar, $100 \mu \mathrm{m}$.

of chemotherapy according to the NECO-95J protocol (16) and heavy-particle radiotherapy (70 Gy) $(n=2)$. Chemotherapy was selected for soft tissue sarcomas that were exceptionally large or in close proximity to vessels or nerves, precluding the achievement of wide margins; chemotherapy was also administered in cases where the margin was positive after surgery. We administered ifosfamide and doxorubicin hydrochloride to all patients with myxoid liposarcoma, synovial sarcoma, and leiomyosarcoma (17). We also administered vincristine, doxorubicin, cyclophosphamide, ifosfamide, and etoposide to patients with Ewing sarcoma (18). In cases of bone sarcoma, chemotherapy was administered to patients with osteosarcoma according to the NECO-95J protocol using the same dosage as that used for adults (16). No lethal side-effects were noted in any of the patients (Table II).

Recurrence. Two patients experienced local recurrence. No evidence of disease (NED) status was maintained in 1 case after a second resection of the osteosarcoma in the tibia 36 months after the first marginal resection. This patient had undergone marginal resection after being misdiagnosed with a giant cell tumor on histological evaluation of the biopsy sample. The other patient had a myxoid liposarcoma of the thigh that recurred 73 months after wide- resection; this patient also achieved NED status after undergoing a second resection. Images from her first MRI showed a myxomatous tumor (Fig. 1A and B). This was resected widely, and the histology was found to be myxoid liposarcoma (Fig. 1C). The surgical margins were inadequate ( $\mathrm{R} 1$ ), and a recurrence occurred in the nerve, 6 years after the surgery (Fig. 2A and B) leading to 


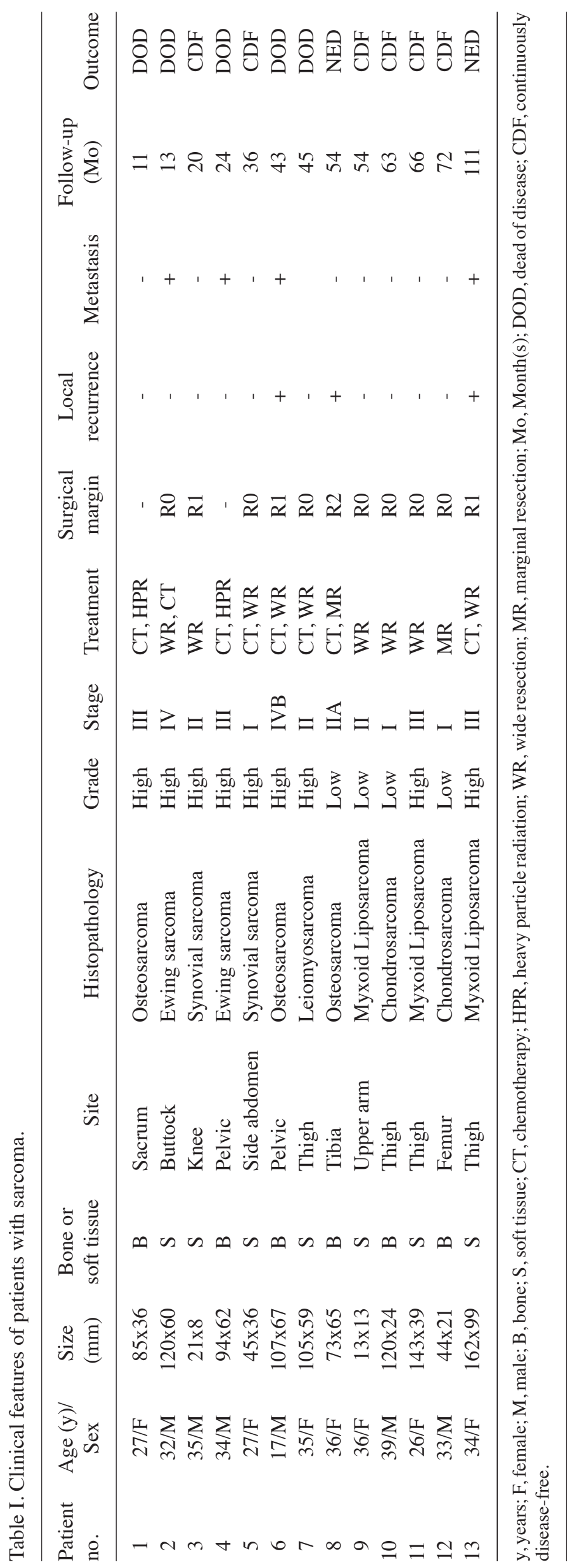


Table II. Chemotherapy toxic effects, worst grade per patient.

\begin{tabular}{|c|c|c|c|c|c|}
\hline Item & Grade 0 & Grade 1 & Grade 2 & Grade 3 & Grade 4 \\
\hline \multicolumn{6}{|l|}{ Hematological } \\
\hline White blood cells & 3 & 2 & 2 & 1 & 0 \\
\hline Neutrophils & 2 & 1 & 3 & 2 & 0 \\
\hline Platelets & 5 & 2 & 1 & 0 & 0 \\
\hline \multicolumn{6}{|l|}{ Biochemical } \\
\hline Creatinine & 0 & 0 & 0 & 0 & 0 \\
\hline AST & 6 & 1 & 1 & 0 & 0 \\
\hline ALT & 6 & 1 & 1 & 0 & 0 \\
\hline \multicolumn{6}{|l|}{ Clinical } \\
\hline Nausea & 2 & 2 & 2 & 0 & 0 \\
\hline Vomiting & 1 & 0 & 0 & 0 & 0 \\
\hline Diarrhoea & 1 & 0 & 0 & 0 & 0 \\
\hline Mucositis & 0 & 0 & 0 & 0 & 0 \\
\hline Alopecia & 1 & 3 & 1 & 0 & 0 \\
\hline Fever & 2 & 0 & 0 & 0 & 0 \\
\hline Infection & 0 & 0 & 0 & 1 & 0 \\
\hline Neurological & 0 & 0 & 0 & 0 & 0 \\
\hline Cardiac & 0 & 0 & 0 & 0 & 0 \\
\hline
\end{tabular}

Toxic effects were assessed using the National Cancer Institute common toxicity criteria (version 1). Data are number of patients (\%). Laboratory data available for 8 patients, clinical data for 6 patients. AST, aspartate aminotransferase; ALT, alanine aminotransferase.

the tumor being removed marginally. The histology revealed recurrent liposarcoma (Fig. 2C).

The clinical results indicated a CDF, NED, and dead of disease (DOD) status in 6,2, and 5 cases, respectively. The inadequate margins ( $\mathrm{R} 1$ or R2) in 4 cases led to recurrence and DOD status in 2 and 1 cases, respectively.

Survival. The 5-year survival rate for the entire cohort was $57.1 \%$ (Fig. 3A). The survival rate of younger patients (15-29 years) was lower than that of their older counterparts ( $\geq 30$ years) ( 37.5 vs. $63.4 \%, P=0.43$, Fig. $3 B$ ). The differences in survival were similar between patients with bone and soft tissue tumors ( 72.0 vs. $64.2 \%, \mathrm{P}=0.53$, Fig. $3 \mathrm{C}$ ). The 5-year survival rate was decreased in patients with high-grade compared to low-grade sarcomas (32.4 vs. $100 \%, \mathrm{P}<0.001$, Fig. 3D). The 5-year survival rate was also decreased in patients with sarcomas located in the trunk compared to in the extremities ( 0 vs. $76.2 \%, \mathrm{P}=0.017$, Fig. $3 \mathrm{E}$ ).

\section{Discussion}

The clinical outcomes in AYAs with BSTS have not improved owing to the lack of actionable data (10). In the present study, we determined the clinical features and outcomes of AYA patients with BSTS.

Three of the major histological types of malignant bone sarcomas among AYAs (based on incidence rates) are osteosarcomas, Ewing sarcomas of the bone, and chondrosarcoma (19). The major histological types of soft tissue sarcomas found in AYAs include rhabdomyosarcomas, synovial sarcomas, leiomyosarcomas, undifferentiated pleomorphic sarcomas, and liposarcomas $(5,19)$. In the present study, almost all AYAs with BSTS had one of the major histological types; however, Ewing sarcoma of the bone, which was found in one patient, is relatively rare in the AYA age group.

Major sarcomas may metastasize to lymph nodes more frequently in AYAs than in younger and older age groups $(20,21)$; lymph node metastatic status was previously found to be the most important prognostic factor in patients with sarcomas $(22,23)$. In the present study, only one patient experienced sequential metastases to the lymph nodes and lung, and subsequently succumbed to the disease.

In general, surgical margins are associated with the prognosis of malignant bone and soft tissue tumors $(24,25)$. Previous findings demonstrated that the surgical margin is associated with the prognosis of malignant bone and soft tissue tumors in AYA patients (26). In the present study, inadequate surgical margins conferred poor prognosis.

Previous findings have shown that 5-year survival rates for AYA patients with BSTS range from 68.7 to $75.3 \%(10,27)$. Being in the AYA age group is an independent negative prognostic factor for patients with cancer (28). In addition, survival rates in AYA patients with osteosarcoma were significantly poorer than those of children $(7,29)$. By contrast, in another study it was shown that being in the AYA age group does not influence the prognosis of patients with bone sarcoma (10). In the present study, the 5-year survival rate was poorer than both the rates reported in previous studies, and that of older patients with sarcoma $(86.02 \%)$ included in the present study (30). These data support the hypothesis that being in the AYA age group is a poor prognostic factor. 
A

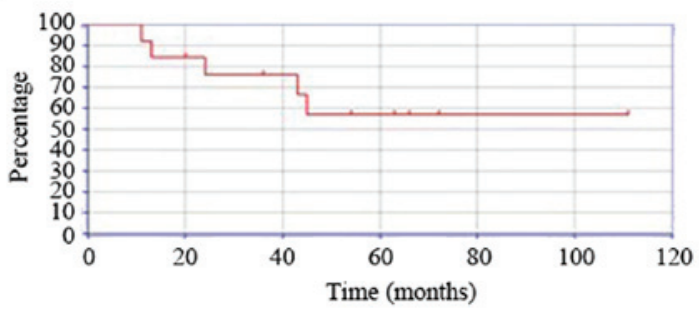

$\mathrm{C}$

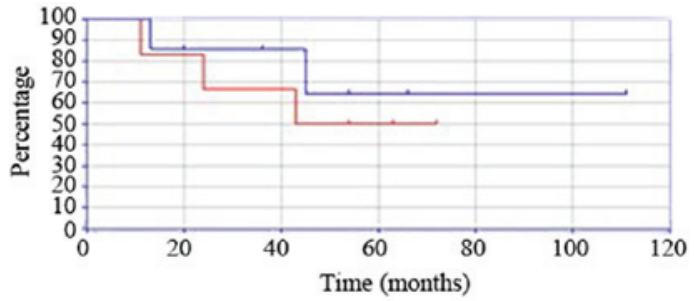

E

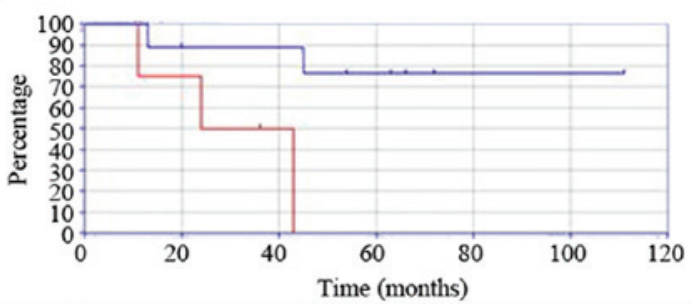

B

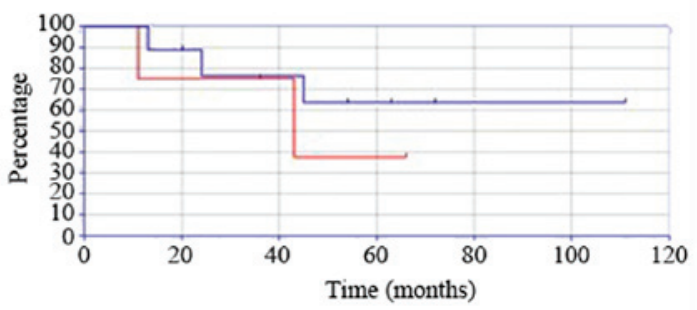

D

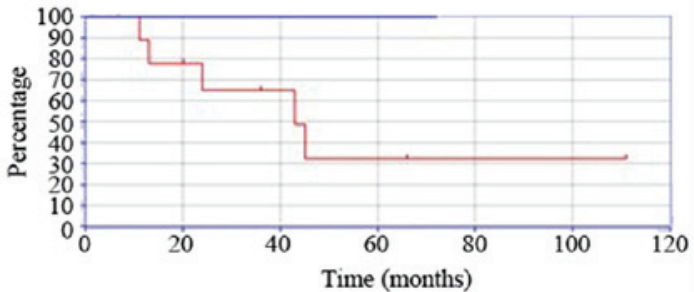

Figure 3. Kaplan-Meier curves showing survival rates in various groups. (A) Survival rates in adolescents and young adults with sarcoma according to age. (B) Survival rates in patients with sarcoma who were 15-29 years (red line) vs. those who were 30 years of age and older (blue line). Survival was poorer in patients with sarcomas of 15-29 years of age. There was no significant difference between these age groups (P=0.43). (C) Survival rates in adolescents and young adults with soft tissue sarcomas (red line) vs. bone sarcoma (blue line). Survival rates were similar in patients of both groups. There was no significant difference according to sarcoma type ( $\mathrm{P}=0.53$ ). (D) Survival rates of adolescents and young adults with high-grade (red line) vs. low-grade sarcoma (blue line). Survival was significantly poorer in the high-grade sarcoma group $(\mathrm{P}<0.001)$. (E) Survival rates in adolescents and young adults with sarcomas of the trunk (red line) vs. extremities (blue line). Survival was significantly poorer in patients with sarcomas of the trunk $(\mathrm{P}=0.017)$.

The prognostic factors for sarcoma in AYA patients have been previously explored $(5,10,31)$. Previous findings have shown that older age, large tumor size, high grade, lack of neoadjuvant chemotherapy, and positive surgical margin adversely influence prognosis (32-35). In the present study, younger patients with sarcomas had poorer 5-year survival rates than that of the older patients. Patients with sarcomas of the trunk had poorer 5-year survival rates than those with sarcomas in the extremities. Patients with high-grade sarcomas also had poorer 5-year survival rates than those with low-grade tumors. Thus, younger age, trunk location, and high-grade status appear to be poor prognostic factors in AYA patients with BSTS.

Our study had certain limitations. First, the number of patients was small. Consequently, statistical analysis was not feasible, and the report was therefore descriptive. Second, the included tumors were considerably diverse. Third, we were unable to compare the outcomes of these patients to those of younger patients with sarcoma, and a future comparative study has been planned.

In conclusion, in the present study, we determined the clinical features and outcomes of AYA patients with BSTS. Younger age, trunk location, and high-grade tumors were associated with poorer 5-year survival rates. Therefore, BSTS located in the trunk or of high-grade should be treated more aggressively in younger AYA patients.

\section{Acknowledgements}

We would like to thank Editage (www.editage.jp) for English language editing.

\section{Funding}

No funding was received.

\section{Availability of data and materials}

The datasets used and/or analyzed during the present study are available from the corresponding author on reasonable request.

\section{Authors' contributions}

$\mathrm{KH}, \mathrm{SN}$, and $\mathrm{NO}$ conceived and designed the study. KH, SN, $\mathrm{NO}$, and MA performed data acquisition. $\mathrm{KH}, \mathrm{SN}$, and MA performed analysis and interpretation of data. $\mathrm{KH}, \mathrm{SN}, \mathrm{NO}$, 
and MA were involved in drafting the manuscript or revising it critically for important intellectual content. KH, SN, NO, and MA gave final approval of the version to be published and agreed to be accountable for all aspects of the work. All authors read and approved the final manuscript.

\section{Ethics approval and consent to participate}

This study was approved by the Ethics Committee of Kindai University Hospital (approval no.: 31-153) (Osaka, Japan). All patients also provided written informed consent for the participation of this retrospective study.

\section{Patient consent for publication}

Not applicable.

\section{Competing interests}

The authors declare that they have no competing interests.

\section{References}

1. Burningham Z, Hashibe M, Spector L and Schiffman JD: The epidemiology of sarcoma. Clin Sarcoma Res 2: 14, 2012.

2. Herzog CE: Overview of sarcomas in the adolescent and young adult population. J Pediatr Hematol Oncol 27: 215-218, 2005

3. Barr RD, Ries LA, Lewis DR, Harlan LC, Keegan TH, Pollock BH and Bleyer WA; US National Cancer Institute Science of Adolescent and Young Adult Oncology Epidemiology Working Grou: Incidence and incidence trends of the most frequent cancers in adolescent and young adult Americans, including 'nonmalignant/noninvasive' tumors. Cancer 122 1000-1008, 2016.

4. Bleyer A, O'Leary M, Barr R and Ries LAG (eds): Cancer epidemiology in older adolescents and young adults 15 to 29 years of age, including SEER incidence and survival: 1975-2000. Bethesda, MD: U.S. Dept. of Health and Human Services, National Institutes of Health, National Cancer Institute, pp205, 2006.

5. Kasper B, Ouali M, van Glabbeke M, Blay JY, Bramwell VH, Woll PJ, Hohenberger P and Schöffski P: Prognostic factors in adolescents and young adults (AYA) with high risk soft tissue sarcoma (STS) treated by adjuvant chemotherapy: A study based on pooled European organisation for research and treatment of cancer (EORTC) clinical trials 62771 and 62931. Eur J Cancer 49: 449-456, 2013.

6. Albritton KH: Sarcomas in adolescents and young adults. Hematol Oncol Clin North Am 19: 527-546, vii, 2005.

7. Keegan TH, Ries LA, Barr RD, Geiger AM, Dahlke DV, Pollock BH and Bleyer WA; National Cancer Institute Next Steps for Adolescent and Young Adult Oncology Epidemiology Working: Comparison of cancer survival trends in the United States of adolescents and young adults with those in children and older adults. Cancer 122: 1009-1016, 2016.

8. Haggar FA, Preen DB, Pereira G, Holman CD and Einarsdottir K: Cancer incidence and mortality trends in Australian adolescents and young adults, 1982-2007. BMC Cancer 12: 151, 2012.

9. Eleutério SJ, Senerchia AA, Almeida MT, Da Costa CM, Lustosa D, Calheiros LM, Barreto JH, Brunetto AL, Macedo CR and Petrilli AS: Osteosarcoma in patients younger than 12 years old without metastases have similar prognosis as adolescent and young adults. Pediatr Blood Cancer 62: 1209-1213, 2015.

10. Fukushima T, Ogura K, Akiyama T, Takeshita K and Kawai A: Descriptive epidemiology and outcomes of bone sarcomas in adolescent and young adult patients in Japan. BMC Musculoskelet Disord 19: 297, 2018.

11. Broders AC: Squamous cell epithelioma of the lip. A study of 537 cases. JAMA 74: 656-664, 1920.

12. Trojani M, Contesso G, Coindre JM, Rouesse J, Bui NB, de Mascarel A, Goussot JF, David M, Bonichon F and Lagarde C: Soft-tissue sarcomas of adults; study of pathological prognostic variables and definition of a histopathological grading system. Int J Cancer 33: 37-42, 1984.
13. Edge SB, Byrd DR and Compton CC (eds): Soft tissue sarcoma. American Joint Committee on Cancer cancer staging manual. 7th edition. New York, Springer, New York, NY, pp291-296, 2010.

14. Edge SB, Byrd DR and Compton CC (eds): Bone. American Joint Committee on Cancer cancer staging manual. 7th edition. New York, Springer, New York, NY, pp281-290, 2010.

15. Gundle KR, Kafchinski L, Gupta S, Griffin AM, Dickson BC, Chung PW, Catton CN, O'Sullivan B, Wunder JS and Ferguson PC: Analysis of margin classification systems for assessing the risk of local recurrence after soft tissue sarcoma resection. J Clin Oncol 36: 704-709, 2018.

16. Iwamoto Y, Tanaka K, Isu K, Kawai A, Tatezaki S, Ishii T, Kushida K, Beppu Y, Usui M, Tateishi A, et al: Multiinstitutional phase II study of neoadjuvant chemotherapy for osteosarcoma (NECO study) in Japan: NECO-93J and NECO-95J. J Orthop Sci 14: 397-404, 2009.

17. Tanaka K, Kawamoto H, Saito I, Yoshimura K, Fukuda H and Iwamoto Y: Preoperative and postoperative chemotherapy with ifosfamide and adriamycin for adult high-grade soft-tissue sarcomas in the extremities: Japan clinical oncology group study JCOG0304. Jpn J Clin Oncol 39: 271-273, 2009.

18. Pretz JL, Barysauskas CM, George S, Hornick JL, Raut CP, Chen YE, Marcus KJ, Choy E, Hornicek F, Ready JE, et al: Localized adult Ewing sarcoma: Favorable outcomes with alternating vincristine, doxorubicin, cyclophosphamide, and ifosfamide, etoposide (VDC/IE)-based multimodality therapy. Oncologist 22: 1265-1270, 2017.

19. Katanoda K, Shibata A, Matsuda T, Hori M, Nakata K, Narita Y, Ogawa C, Munakata W, Kawai A and Nishimoto H: Childhood, adolescent and young adult cancer incidence in Japan in 2009-2011. Jpn J Clin Oncol 47: 762-771, 2017.

20. Mazeron JJ and Suit HD: Lymph nodes as sites of metastases from sarcomas of soft tissue. Cancer 60: 1800-1808, 1987.

21. Al-Refaie WB, Andtbacka RH, Ensor J, Pisters PW, Ellis TL, Shrout A, Hunt KK, Cormier JN, Pollock RE and Feig BW: Lymphadenectomy for isolated lymph node metastasis from extremity soft-tissue sarcomas. Cancer 112: 1821-1826, 2008.

22. Johannesmeyer D, Smith V, Cole DJ, Esnaola NF and Camp ER: The impact of lymph node disease in extremity soft-tissue sarcomas: A population-based analysis. Am J Surg 206: 289-295, 2013.

23. Riad S, Griffin AM, Liberman B, Blackstein ME, Catton CN Kandel RA, O'Sullivan B, White LM, Bell RS, Ferguson PC and Wunder JS: Lymph node metastasis in soft tissue sarcoma in an extremity. Clin Orthop Relat Res: 129-134, 2004.

24. Fujiwara T, Medellin MR, Sambri A, Tsuda Y, Balko J, Sumathi V, Gregory J, Jeys L and Abudu A: Preoperative surgical risk stratification in osteosarcoma based on the proximity to the major vessels. Bone Joint J 101-B: 1024-1031, 2019.

25. Vodanovich DA, Spelman T, May D, Slavin J and Choong PFM: Predicting the prognosis of undifferentiated pleomorphic soft tissue sarcoma: A 20-year experience of 266 cases. ANZ J Surg 89: 1045-1050, 2019.

26. Janeway KA, Barkauskas DA, Krailo MD, Krailo MD, Meyers PA, Schwartz CL, Ebb DH, Seibel NL, Grier HE, Gorlick R and Marina N: Outcome for adolescent and young adult patients with osteosarcoma: A report from the children's oncology group. Cancer 118: 4597-4605, 2012.

27. Avila JC, Livingston JA, Rodriguez AM, Kirchhoff AC, Kuo YF and Kaul S: Disparities in adolescent and young adult sarcoma survival: Analyses of the texas cancer registry and the national SEER data. J Adolesc Young Adult Oncol 6: 681-687, 2018.

28. Tricoli JV, Seibel NL, Blair DG, Albritton K and Hayes-Lattin B: Unique characteristics of adolescent and young adult acute lymphoblastic leukemia, breast cancer, and colon cancer. J Natl Cancer Inst 103: 628-635, 2011.

29. Khamly KK, Thursfield VJ, Fay M, Desai J, Toner GC, Choong PF, Ngan SY, Powell GJ and Thomas DM: Gender-specific activity of chemotherapy correlates with outcomes in chemosensitive cancers of young adulthood. Int J Cancer 125: 426-431, 2009.

30. Hashimoto K, Nishimura S, Hara Y, Oka N, Tanaka H, Iemura $S$ and Akagi M: Clinical outcomes of patients with primary malignant bone and soft tissue tumor aged 65 years or older. Exp Ther Med 17: 888-894, 2019.

31. White VM, Orme LM, Skaczkowski G, Pinkerton R, Coory M, Osborn M, Bibby H, Nicholls W, Conyers R, Phillips MB, et al: Management of sarcoma in adolescents and young adults: An Australian population-based study. J Adolesc Young Adult Oncol 8: 272-280, 2019. 
32. Duchman KR, Gao Y and Miller BJ: Prognostic factors for survival in patients with Ewing's sarcoma using the surveillance, epidemiology, and end results (SEER) program database. Cancer Epidemiol 39: 189-195, 2015.

33. Bertrand TE, Cruz A, Binitie O, Cheong D and Letson GD: Do surgical margins affect local recurrence and survival in extremity, nonmetastatic, high-grade osteosarcoma? Clin Orthop Relat Res 474: 677-683, 2016.

34. Buchner M, Bernd L, Zahlten-Hinguranage A and Sabo D: Primary malignant tumours of bone and soft tissue in the elderly. Eur J Surg Oncol 30: 877-883, 2004.
35. Duchman KR, Gao Y and Miller BJ: Prognostic factors for survival in patients with high-grade osteosarcoma using the surveillance, epidemiology, and end results (SEER) program database. Cancer Epidemiol 39: 593-599, 2015.

(i) $(9$ This work is licensed under a Creative Commons Attribution-NonCommercial-NoDerivatives 4.0 International (CC BY-NC-ND 4.0) License. 